\title{
M. Butor, Par le temps qui court
}

\section{Anna Bucarelli}

\section{OpenEdition}

\section{Journals}

\section{Edizione digitale}

URL: http://journals.openedition.org/studifrancesi/10598

DOI: 10.4000/studifrancesi. 10598

ISSN: 2427-5856

\section{Editore}

Rosenberg \& Sellier

\section{Edizione cartacea}

Data di pubblicazione: 1 décembre 2017

Paginazione: 584-585

ISSN: 0039-2944

\section{Notizia bibliografica digitale}

Anna Bucarelli, «M. Butor, Par le temps qui court», Studi Francesi [Online], 183 (LXI | III) | 2017, online dal

01 février 2018, consultato il 22 janvier 2021. URL: http://journals.openedition.org/studifrancesi/ 10598 ; DOI: https://doi.org/10.4000/studifrancesi.10598

Questo documento è stato generato automaticamente il 22 janvier 2021.

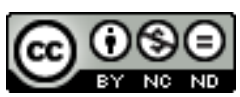

Studi Francesi è distribuita con Licenza Creative Commons Attribuzione - Non commerciale - Non opere derivate 4.0 Internazionale. 


\title{
M. Butor, Par le temps qui court
}

\author{
Anna Bucarelli
}

\section{NOTIZIA}

MICHEL BUTOR, Par le temps qui court, choix de Michel Butor, préface de Jean-Michel Maulpoix et texte de Mireille Calle-Gruber, Paris, La Différence, 2016, 188 pp.

1 Se la forma antologica è quella che meglio di ogni altra sa raccogliere, secondo Mireille Calle-Gruber («de rosée d'épices de sel», pp. 23-24) «les fulgurations, les rythmes, les éblouissements» della poesia di Michel Butor, questa antologia, con quarantuno testi scelti dall'autore e composti in oltre sessant'anni di scrittura, permette al contempo di delineare la traiettoria poetica butoriana. In tal senso, le temps qui court evoca innanzitutto il tempo di una vita dedicata alla letteratura; «une vie pleine de vies multiples» che vede lo scrittore «en explorateur des langues et des imaginaires, en orpailleur du verbe, en archéologue du genre humain, en témoin de ses détresses et de ses espoirs qu'il partage» (p. 23). Ma, d'accordo con Mireille Calle-Gruber, le temps qui court è anche il tempo presente e unico del vissuto con le sue epifanie, o le istantanee del quotidiano che occupano lo spazio di una quartina o di qualche ottosillabo (come nel «Portrait de l'artiste en salopette»); infine, il refrain par le(s) temps qui cour(en)t allude a una «actualité intempestive, cruelle, désespérante» (p. 24) e alle sofferenze del mondo contemporaneo, dalle guerre alle violazioni dei diritti umani (come in «Le crépuscule sur Bagdad», «L'aurore sur Bagdad», «Réclamation universelle des droits de l'homme»). E, si potrebbe aggiungere, le temps qui court è anche quello personificato in «Stèle pour le temps» («Les anciens lui accordaient | longue barbe et grandes ailes | des membres très amaigris | tous les signes de fatigue | mais pourtant courant toujours | volant sur tous les obstacles | sans pouvoir se reposer», p. 136) la cui corsa richiama quella del secolo concluso in «Adieu au siècle» (pp. 111-115), con dieci strofe per dieci decenni, e quella dell'era cristiana in «Récapitulation 2000» (pp. 116-127), con venti strofe per venti secoli. 
2 La Prefazione di Jean-Michel Maulpoix («Flèche de tout bois», 7-21) propone un excursus della produzione poetica butoriana di cui richiama alcuni tratti salienti, dal piacere della contrainte formelle all'inventiva senza freni di impronta surrealista; dalla ripresa e reinvenzione di forme dimenticate, come la ballata e il madrigale, e di elementi della tradizione, come le commedie di Molière, ai dispositivi verbali che traducono sulla pagina la «moderne mobilité des voix et des temps» (p. 16); dalle enumerazioni e lunghe liste che repertoriano e "producono" il dehors (p. 10) alle reticenze del dedans; dal «jubilatoire il y a» - ispirato a Rimbaud e Apollinaire - «affirmé et réaffirmé malgré tout ce qui s'y oppose et voudrait le nier» (p. 12) al sentimento geografico del viaggiatore che declina il mondo al presente - come il Cendrars di Au cœur du monde - o descrive tribù immaginarie non senza ricordare gli "altrove" di Henri Michaux. Per caratterizzare nel suo insieme la scrittura poetica butoriana Maulpoix ricorre a due verbi: colorer, che riprende da Mireille Calle-Gruber, e rafraîchir, nel senso di «remettre de la couleur sur un monde qu'empoisse une langue banale et grise» (p. 14), ovvero di ridare vita alla lingua per riappropriarsi del mondo. Ed è appunto per «conjurer la noirceur de l'époque et pour faire résonner un appel sensuel à la vie bien vivante que Michel Butor fait flèche de tout bois» (p. 9). Terreno di una sperimentazione sempre più libera, la sua scrittura poetica assume forme estremamente varie e si ibrida con altri generi e con le arti in una concezione essenzialmente dinamica della letteratura, dove rappresenta, al contempo, l'opera di un romanziere che «construit l'aventure du langage à la manière d'une fiction», di un artista «qui illustre et qui expose la langue», di un drammaturgo «qui fait évoluer les mots comme les personnages sur la scène de la page blanche» e, ancora, di un critico «qui réfléchit dans le poème son propre travail» (p. 20). La poesia di Butor, «sous toutes ses formes», rappresenta la «liberté même que l'écriture a conquise» (p. 7). E in questa libertà, nella ritrovata solidarietà di parole e cose, l'uomo si riconcilia con il suo mondo. 